\title{
O significado da hospitalização para a criança pré-escolar: um modelo teórico
}

\author{
THE MEANING OF HOSPITALIZATION FOR THE PRE-SCHOOL CHILD: A THEORETICAL MODEL \\ EL SIGNIFICADO DE LA HOSPITALIZACIÓN PARA EL NIÑO EN EDAD \\ PRE-ESCOLAR: UN MODELO TEÓRICO
}

\author{
Circéa Amália Ribeiro', Margareth Angelo²
}

\section{RESUMO}

Este estudo teve como objetivo compreender o significado de estar hospitalizada, para a criança pré-escolar. Os referenciais teóricos foram o Interacionismo Simbólico e a teoria de Vygotsky sobre a brincadeira simbólica da criança e o referencial metodológico foi a Teoria Fundamentada nos Dados. Participaram do mesmo 11 crianças de três a seis anos de idade. As estratégias de coleta de dados foram: observação participante, entrevista com as crianças, mediada pelo Brinquedo Terapêutico e entrevista com as mães. A análise dos dados permitiu construir o modelo teórico Crescendo com a presença protetora da mãe, que evidencia a vulnerabilidade, a força da criança e a proteção recebida da mãe, para enfrentar o mistério e o terror da hospitalização.

\section{DESCRITORES}

Enfermagem pediátrica.

Criança hospitalizada.

Jogos e brinquedos (psicologia).

Mãe acompanhando filho no

hospital.

\begin{abstract}
This study was aimed at comprehending the meaning of being hospitalized for pre-school children. The theoretical references were the Symbolic Interactionism and Vygotsky's theory on the child's symbolic play. The methodological referential was the Theory Based on Data. Eleven children between the ages of 3 and 6 took part in the survey. The strategies for data collection were: participative observation, interviews with the children mediated by the Therapeutic Toy, and interviews with the mothers. The analysis of the data made possible the construction of the technical model Growing up with the mother's protective presence, which puts in evidence the vulnerability, the child's force and the protection given by the mother to face the mystery and the fear of hospitalization.
\end{abstract}

\section{KEY WORDS}

Pediatric nursing.

Child, hospitalized.

Play and playthings (psychology). Mother with child in hospital.

\section{RESUMEN}

En este estudio se tuvo como objetivo comprender el significado que tiene para un niño preescolar, estar hospitalizado. Los referenciales teóricos fueron el Interaccionismo Simbólico y la teoría de Vygotsky sobre el juego simbólico del niño y el referencial metodológico fue la Teoría Fundamentada en los Datos. Participaron del mismo 11 niños de tres a seis años de edad. Las estrategias de recolección de datos fueron: observación participante, entrevista con los niños, mediado por el Juguete Terapéutico y entrevista con las madres. El análisis de los datos permitió construir el modelo teórico Creciendo con la presencia protectora de la madre, que evidencia la vulnerabilidad, la fuerza del niño y la protección recibida de la madre, para enfrentar el misterio y el terror de la hospitalización.

\section{DESCRIPTORES}

Enfermería pediátrica.

Niño hospitalizado.

Juego e implementos de juego (psicologia).

Madre acompañando hijo en hospital.
1 Enfermeira. Professor Adjunto do Departamento de Enfermagem da Universidade Federal de São Paulo - UNIFESP. circea@denf.epm.br

2 Enfermeira. Professor Titular do Departamento de Enfermagem MaternoInfantil e Psiquiátrica da Escola de Enfermagem da USP.

angelm@usp.br. 
Circéa Amália Ribeiro

Margareth Angelo

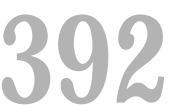

Rev Esc Enferm USP 2005; 39(4):391-400.

\section{INTRODUÇÃO}

Entre as situações que ao serem vivenciadas pela criança são consideradas determinadoras de estresse encontram-se a doença e a hospitalização, que podem fazer com que a criança fique emocionalmente traumatizada em maior grau do que está fisicamente doente $^{(1)}$. Ao ser hospitalizada a criança encontra-se duplamente doente; além da patologia física, ela sofre de outra doença, a própria hospitalização, que se não for adequadamente tratada, deixará marcas em sua saúde mental.

Na literatura acerca da hospitalização da criança distinguem-se dois períodos, cujos trabalhos apresentam ênfases diferentes. No primeiro, que vai de 1950 até meados da década de 80, a ênfase dos trabalhos repousa nos efeitos maléficos à saúde física e mental da criança decorrentes da separação da família, especialmente de sua mãe, que determina sofrimento e desencadeia mudanças no seu comportamento, não só durante a hospitalização como também após a alta ${ }^{(2-6)}$.

As evidencias geradas por esses estudos foram: as três fases de resposta emocional da criança à separação da mãe: protesto, desesperança e negação ${ }^{(2)}$; os danos da privação materna que pode ocorrer durante a hospitalização, especialmente se esta for prolongada e a criança for menor que cinco anos de idade ${ }^{(3)}$; o risco do hospitalismo, o qual é descrito como um quadro de reações bastante complexas, apresentado por crianças hospitalizadas, inclusive com sintomas clínicos que podem agravar ou se confundir com os sintomas da própria doença que determinou a internação, dificultando o diagnóstico e o tratamento ${ }^{(4)}$; as reações apresentadas pelas crianças, após a alta como: insônia, pesadelos, medo excessivo, seguir a mãe freqüentemente e ter dificuldade em separar-se dela, ou, contrariamente, rejeitá-la, além do aparecimento de distúrbios reativos de conduta como enurese, roer unhas, maneirismos entre outras ${ }^{(5-6)}$.

No segundo período, a partir da metade da década de 80 , os trabalhos passam a discutir, principalmente, os benefícios da presença da mãe para a criança hospitalizada, tais como: redução do tempo de hospitalização e melhora do comportamento após a alta; declínio da incidência de infecção cruzada e de complicações pós-operatórias; aumento do senso de segurança por não haver mais a ansiedade da separação; maior acurácia de balanço hídrico e maior facilidade de coleta de material para exames, além de as crianças ficavam menos sozinhas, dormirem melhor e manterem mais interações sociais com menor número de adultos ${ }^{(7-8)}$.
Os estudos passam também a ressaltar os conflitos entre a mãe e a equipe e as tentativas de mediação desses conflitos. Enfocam que os conflitos surgem em função da diferença de expectativas e de poder de decisão sobre o cuidado da criança, entre os pais e a equipe, assim como em decorrência do estresse e do sofrimento determinados pela vivência que os procedimentos causam tanto na criança e nos pais, como na própria equipe ${ }^{(9-13)}$.

Outra característica dessa fase é a realização de trabalhos que se preocupam em discutir, mais profundamente, diferentes fontes de estresse da criança hospitalizada, além da ansiedade da separação, tais como o medo da dor, das agulhas, e de ficar sem a mãe, e a falta de controle sobre as situações, inclusive de seu corpo ${ }^{(14-15)}$.

Surgem ainda alguns trabalhos que discutem aspectos da hospitalização a partir de relatos das próprias crianças, as quais expressam o sofrimento advindo da vivência dos procedimentos diagnósticos e terapêuticos, especialmente os que envolvem a utilização de agulhas, assim como de outros aspectos da hospitalização: a diferença de alimentação, as restrições para poder brincar e o próprio fato de ter que permanecer no hospital ${ }^{(16-22)}$. Elas referem-se ao hospital como um local desconhecido, estranho, de anonimato, de torturas e suplícios, de agressões físicas com intenções punitivas, de solidão, de tristeza e saudades; um local desagradável, onde é proibido brincar, cuja função é evitar a morte em casa $^{(19)}$. Algumas crianças portadoras de doença crônica chegam a pedir um hospital diferente, onde não haja doença ${ }^{(21)}$. Elas também referem que se percebem cuidadas no hospital quando experienciam carinho e afeição da equipe e dos familiares e quando são ajudadas no momento que precisam $^{(22)}$.

Tais estudos foram realizados principalmente com crianças de idade escolar, que foram entrevistadas tanto formalmente como por meio de técnica projetiva, ou que preencheram um check-list. Quanto à criança de idade pré-escolar inexistem estudos nos quais tenha sido ouvida, a respeito do significado que tem, para ela, estar hospitalizada. Este estudo teve como objetivo compreender o significado de estar hospitalizada, para a criança préescolar.

\section{METODOLOGIA}

A coleta e a análise dos dados foi guiada pela Teoria Fundamenta nos Dados (TFD) que visa descrever conceitos que emergem dos dados e interpreta a relação entre estes, permitindo a construção 
de modelos teóricos ${ }^{(23)}$. Como referenciais teóricos utilizou-se o Interacionismo Simbólico (IS), uma perspectiva da análise das experiências humanas que tem como foco de estudo a natureza da interação ${ }^{(24)}$ e a Teoria de Vygotsky sobre a brincadeira simbólica da criança ${ }^{(25)}$.

\section{Local e sujeitos da pesquisa}

O estudo foi realizado na unidade de internação pediátrica de um hospital escola da cidade de São Paulo, que atende crianças com patologias diversas. Antes de seu início o projeto foi avaliado e aprovado pela Comissão de Ética da instituição onde os dados foram coletados, assim como, antes da coleta dos dados, os responsáveis assinaram o termo de consentimento informado e as crianças foram consultadas quanto ao seu desejo de participação.

Participaram do mesmo 11 crianças com idade entre três a seis anos, de ambos os sexos, hospitalizadas por diagnósticos diversos, agudos e crônicos, e que estivessem em condições de brincar, isto é, mantendo estado geral não grave e contatuando com o meio ambiente.

Esse número de participantes foi determinado pelo processo de amostragem teórica, configurando-se, assim, à medida que se realizava a análise dos dados e esta suscitava reflexões que levava à coleta de novos dados, para que as categorias pudessem ser desenvolvidas e densificadas. Desta forma constituíram-se três grupos amostrais: O primeiro foi formado por três crianças que já haviam tido uma ou duas experiências anteriores de hospitalização: duas delas, uma de seis e outra de três anos, eram portadoras de doenças crônicas agudizadas, sendo uma hepática e a outra reumática; a terceira criança, com seis anos, tinha um problema endócrino agudo.

O segundo compôs-se de cinco crianças que estavam sendo hospitalizadas pela primeira vez, sendo anteriormente consideradas sadias: uma, com três anos, era portadora de doença renal crônica, mas em fase inicial; a segunda, com quatro anos, havia sido submetida à amputação do hálux por necrose pós-traumática; a terceira, com quatro anos, tinha infecção respiratória aguda com derrame pleural; as outras duas, ambas com seis anos, estavam hospitalizadas para tratamento cirúrgico de retirada de tumores malignos, um cerebral e outro abdominal.

O terceiro grupo foi constituído por três crianças que já haviam tido várias experiências anteriores de hospitalização: uma, com cinco anos, apresentava doença reumática agudizada e complicações gástricas pelo uso de medicamentos; a segunda, com quatro anos, era portadora de doença hematooncológica, já próxima da fase terminal e a terceira, de seis anos e três meses era uma criança com cardiopatia crônica, utilizava marcapasso que já havia sido substituído várias vezes e estava internada, pela nona vez, em decorrência de uma manifestação de Steve-Johnson subseqüente ao uso de medicamento analgésico.

\section{Coleta dos dados}

As estratégias utilizadas para a coleta dos dados foram:

- Observação participante utilizada para observar como as crianças se comportavam, como agiam e interagiam e que diálogos mantinham com seus pais, com as outras crianças e com os vários profissionais da equipe hospitalar, nas diferentes situações que compõem o cotidiano da hospitalização, tais como higiene, alimentação, procedimentos terapêuticos, recreação.

- Entrevista com as crianças, mediada pelo Brinquedo terapêutico (BT) uma vez que, por serem crianças pré-escolares, é particularmente difícil compreender suas mensagens unicamente pela linguagem verbal, devido aos recursos limitados que elas possuem nesse tipo de comunicação.

O BT se baseia na função catártica do brinquedo e tem sido utilizado pelos enfermeiros não só como um meio de alívio para as tensões impostas à criança, mas também como uma possibilidade de comunicação pela qual podem dar explicação e receber informações da criança, do que as situações significam para ela ${ }^{(26)}$. Cada uma das crianças foi submetida a uma ou duas sessões de brinquedo que foram conduzidas de maneira não diretiva, obedecendo aos princípios da técnica ${ }^{(26)}$.

Como utilizamos o brinquedo com o objetivo de entrevistar a criança, fazia-se a ela a seguinte pergunta orientadora: Vamos brincar de uma criança que está no hospital? e, durante o desenrolar da brincadeira, eram formuladas perguntas sobre a situação imaginária que estava sendo dramatizada, a fim de estimular sua verbalização e assim obtermos mais dados a respeito do significado da situação para ela. O material utilizado nas sessões de brinquedo constituiu-se de: figuras representativas da família, figuras representativas da equipe hospitalar, objetos de uso doméstico e de uso hospitalar, carro, revólver, telefone, mamadeira e material para desenho e pintura. Para que as atividades da brincadeira fossem captadas detalhadamente, as sessões foram filmadas em vídeo e depois transcritas na íntegra, exceto em um dos casos que a criança 
Circéa Amália Ribeiro Margareth Angelo não permitiu a filmagem e então as ocorrências foram anotadas no seu decorrer.

- Entrevista com as mães, na qualidade de informante da experiência da criança, utilizadas para que pontos levantados pelas crianças nas brincadeiras, ou aspectos das interações observadas com elas pudessem ser clareados, uma vez que a criança nem sempre conseguias fazê-lo, em virtude do incompleto desenvolvimento do discurso narrativo da criança pré-escolar ${ }^{(27)}$. Essas entrevistas foram gravadas e depois transcritas na íntegra e eram iniciadas com uma pergunta aberta: Como a senhora percebe que está sendo, para seu filho/a, estar internado /a no hospital?

\section{Análise dos dados}

Como é preconizada pela TFD, a análise dos dados foi acontecendo simultaneamente à coleta dos mesmos, de forma constante e comparativa, seguindo os seguintes passos: codificação aberta que consiste em identificar e analisar cuidadosamente os dados e conceituá-los em forma de códigos; categorização, que consiste em agrupar os códigos por similaridades e diferenças, formando categorias; codificação teórica, processo de especificar as categorias a um fenômeno, a partir de aspectos que dela se sobressaem; identificação e compreensão da categoria central, que constitui o elo entre as categorias e construção do Modelo Teórico representativo da experiência ${ }^{(28)}$.

\section{RESULTADOS}

Os dados emergentes permitiram a construção do modelo teórico Crescendo com a presença protetora da mãe (Figura 1) representativo da experiência de vivenciar a hospitalização para a criança préescolar. O modelo descreve uma história de sofrimento, que a criança expressa pela sua vulnerabilidade, mas também de força, ao enfrentar a hospitalização, contando com presença de sua mãe $\mathrm{e}^{(29)}$.

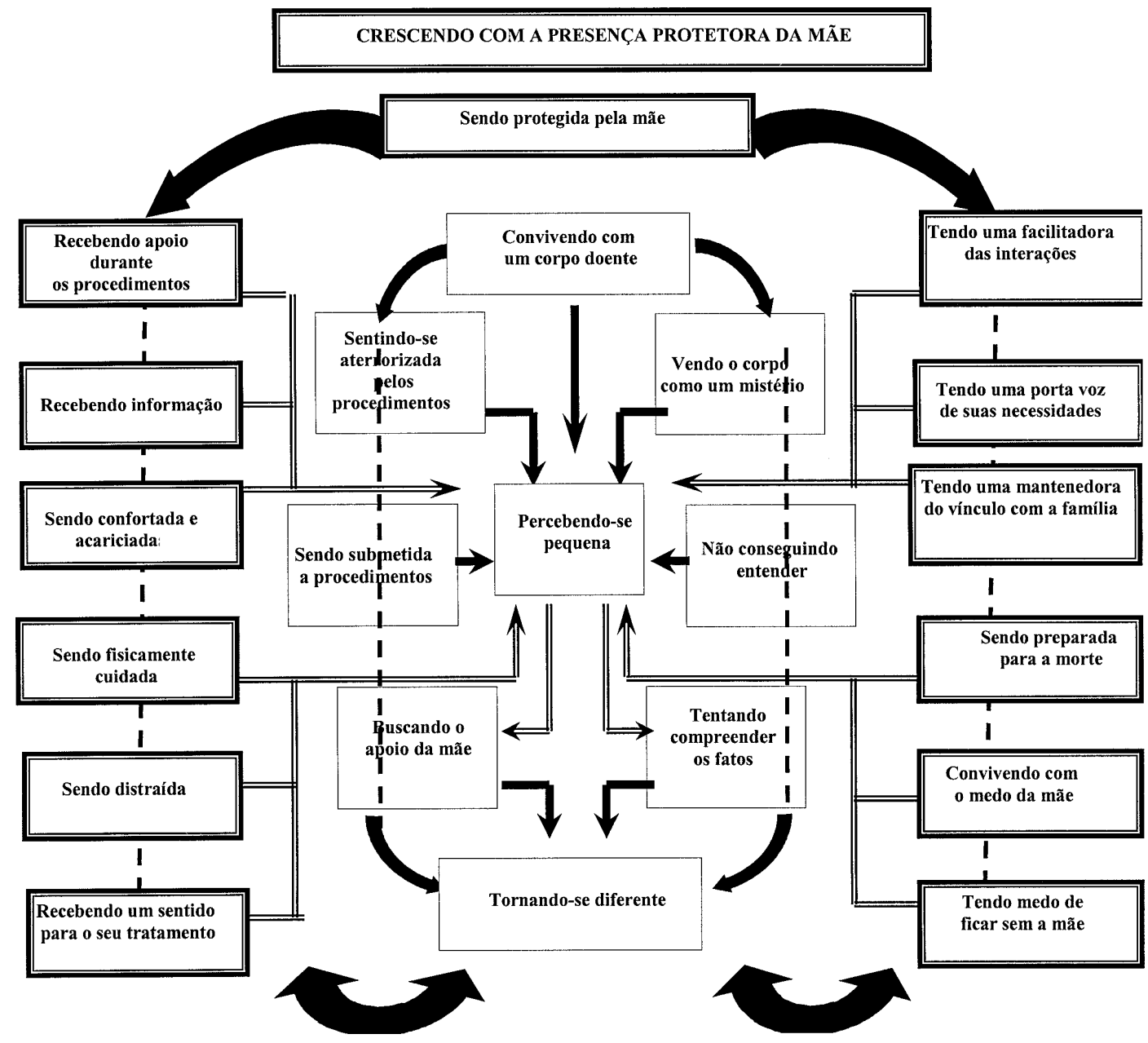

Figura 1. O Modelo Teórico: crescendo com a presença protetora da mãe 
Demonstra também a interação entre as categorias que compõe os dois fenômenos representativos da vulnerabilidade e da força da criança, Convivendo com o mistério e o terror e Enfrentando o mistério e o terror com a proteção da $m \tilde{a} e$, indicando que sua trajetória, e que as estratégias utilizadas pela criança no enfrentamento da situação, ocorrem simultaneamente, exercendo entre si efeitos mútuos, interdependentes e inter-relacionados.

\section{Convivendo com o mistério e o terror}

No centro da figura está representada a vulnerabilidade da criança na vivência da experiência da hospitalização, compondo-se de categorias que descrevem as várias facetas do sofrimento vivenciado por ela quando é hospitalizada. Abrange aspectos inevitáveis da experiência e as dificuldades que a acompanham, como a convivência com a dor e o mal-estar, a submissão a restrições, a constante exploração de seu corpo e a realização de inúmeros procedimentos dolorosos, invasivos e geralmente desconhecidos. A forma como essa experiência é manejada pela equipe hospitalar, aliada à incapacidade da criança pré-escolar em lidar com o abstrato, com a temporalidade dos fatos e com as relações de causa e efeito, fazem com que a experiência se apresente a ela de difícil compreensão e portanto misteriosa e aterrorizante, levando a criança, que já é fisicamente muito menor que o adulto, a perceber-se realmente como pequena, perante a essa experiência.

Convivendo com um corpo doente é o elemento -chave, desencadeador dessa vivência da criança. A própria hospitalização é determinada pelo fato de seu corpo estar doente e necessitar de tratamento ou exames diagnósticos que demandam sua presença no hospital. A convivência com este corpo não é uma convivência tranqüila; sua preocupação não se refere à doença propriamente dita ou à sua gravidade, mas às consequiências do estar doente e hospitalizada, ou seja, às modificações ocorridas em seu corpo; à dor, ao mal estar e ao desconforto; às restrições impostas.

Pesquisadora $^{(a)}(\mathbf{P})$ : Vamos brincar de uma criança que está no hospital? Criança(C): balança positivamente a cabeça. P: Vamos. Então vamos. C olha pra mim e diz: Olha o tamanho da minha barriga. Faz expressão fisionômica e olhar de tristeza, e passa a mão esquerda restringida com uma tala onde está instalado um escalpe heparinizado, pela testa. P: Tamanho de sua barriga? Você está achando que sua barriga está grande? $\mathbf{C}$ balança positivamente a cabeça. (Sessão de Brinquedo= SB)
Como conseqüência da difícil convivência com esse corpo doente, a criança adota algumas estratégias: reclamando da dor, do mal estar, do desconforto, protestando contra as restrições e evitando interagir.
Mãe(M): Noutro dia ela teve assim uma dor de
espernear; aí ela começou a gritar e disse: Se-
nhor, por que eu estou desse jeito?, que foi que
eu fiz? por que você me deixa sofrer assim?
(Entrevista com a mãe = EM)

C pega o telefone, tenta girar o disco que não funciona direito. $\mathbf{P}$ acerta a posição do disco, encaixando-o. M: Já telefonou hoje, A.P.? C balança negativamente a cabeça. M: Vai telefonar pra alguém? C: Pro pai. Disca uns números, espera e fala: Alô! em seguida desliga o telefone, batendo com força. M: Ué, não falou não? C: Ele não está e afasta o telefone bruscamente $(S B)$

Outra fonte de sofrimento da criança é o fato de ela estar Vendo o corpo como um mistério por não conseguir entender aquilo que está ocorrendo em seu corpo, o qual deve ter algo além das diferenças que ela consegue ver, pois é constantemente mexido e examinado pelas pessoas do hospital; algo que se constitui em um grande mistério que só pode ser desvendado com a ajuda de alguns instrumentos que parecem ser a chave para desvelá-lo, como o estetoscópio, o termômetro, o aparelho de pressão arterial. Aliás, durante as sessões de brinquedo, as crianças dramatizaram intensamente exame físico nos bonecos, nelas mesmas, em seus pais e na pesquisadora, como que tentando entender o que seu corpo tem de tão misterioso e demonstrando a dificuldade que têm em compreender e interagir com este corpo.

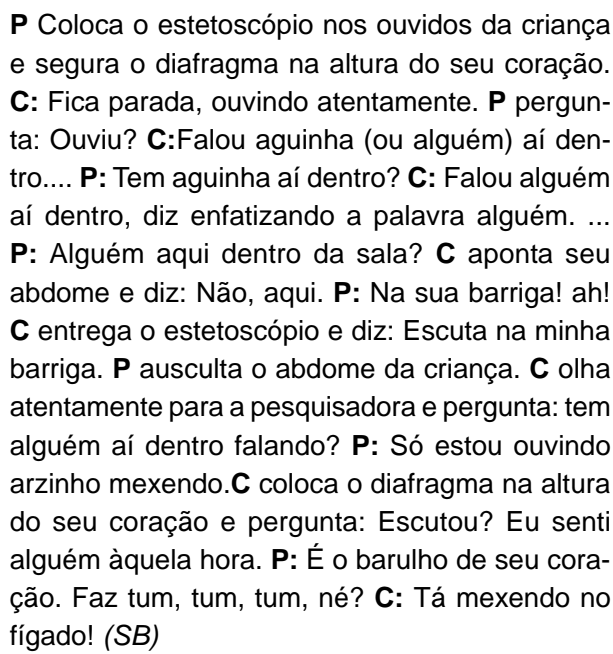

A criança também não entende os motivos dos tratamentos e exames, assim como das restrições a (a) Pesquisadora responsável pela coleta de dados

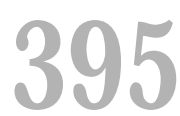

Rev Esc Enferm USP 2005; 39(4):391-400. 
Circéa Amália Ribeiro Margareth Angelo que é constantemente submetida pelo fato de ter um corpo doente, como revela outro componente chave da vivência da hospitalização, Não conseguindo entender.

P: K, você sabe o que veio fazer aqui? $\mathbf{C}$ balança a cabeça positivamente. P: Sabe? O que é que você veio fazer? C: Eu vim me tratar. Acho que eu vou operar a barriga. P: Ah! a barriga. $E$ por que é que você tem que operar a barriga? C: Isso eu não sei , não. Para dizer a verdade, essa história de operação, eu não entendi muito bem isso tudo não. (Nota de Observação=NO)

No decorrer de toda a hospitalização a criança é constantemente submetida a inúmeros procedimentos. Sendo submetida a procedimentos demonstra como se dá o movimento da criança ser submetida aos procedimentos, durante os quais seu corpo é manuseado e invadido, não só em virtude do próprio procedimento intrusivo, mas pela forma como é realizado, com pouca ou nenhuma comunicação da equipe hospitalar, da qual apenas eventualmente, a criança recebe algum auxílio com o objetivo de ajudála a enfrentar a sofrida situação.

Duas Auxiliares de Enfermagem(AE) aproximam-se do berço com a bandeja de material e uma delas fala: Vamos pegar já a veinha dele então, deita ele aqui. $\mathbf{M}$ coloca a criança na cama e afasta-se para junto dos pés da mesma. Uma AE pega a agulha para puncionar a veia e diz: Vai ser rapidinho. A outra $\mathbf{A E}$ restringe o ombro da criança enquanto a primeira punciona a veia rapidamente e hepariniza o escalpe. AE se afastam. (NO)

Além disso, a realização dos procedimentos determina a vivência de outras situações difíceis tais como ser separada de sua da mãe; receber ordens relativas ao local ou a ações que ela deve realizar para que o procedimento possa ser efetuado; ser convencida a colaborar e ouvir comentários sobre o procedimento ou sobre o seu comportamento durante o mesmo.

Médica(Md)...é um Teste de Tolerância à Glicose, mas acho que vai perder, porque não se consegue colher o sangue ... Enfermeira(E): Ela deixou pegar muito bem a veinha da primeira vez, quando tomou a glicose, mas depois, pra colher o sangue, da outra vez, já foi mais difícil e ela começou a chorar e a se mexer; é difícil de achar e quando acha ela se mexe e perde. Vou tentar mais uma vez e se não der acho que vou desistir. (NO)

A vivência dos procedimentos mostra-se, portanto, como uma situação mais do que difícil e ameaçadora; é uma situação aterrorizante para a crian- ça. Sentindo-se aterrorizada pelos procedimentos, descreve, assim, as ações, reações e sentimentos da criança decorrentes da vivência dos procedimentos, tais como sentir medo, sentir-se machucada, não querer e ter que se submeter, nem sempre expressar o que sente, deixar de reagir, viver num constante estado de alerta, sentir raiva, sentir-se ameaçada, sentir-se aliviada quando o procedimento termina. $\mathrm{O}$ medo da criança é tão grande que transcende a realidade do procedimento de fato e chega a ter um significado de morte.

\begin{abstract}
AE passa em frente ao seu berço com uma seringa, para administrar o medicamento no escalpe de outra criança, dizendo: Só o remedinho, tá? C começa a chorar forte e fala em tom alto de voz: Não, eu tô com medo. $\mathbf{M}$ vira-se para ela e diz: Não vai fazer nada não. $\mathbf{C}$ continua chorando e dizendo: Eu tô com medo, com muito medo. $\mathbf{P}$ aproxima-se e pergunta: Medo, medo de quê? C: Medo da médica e chora mais forte ainda. P: Por que você tem medo da médica? M: Ela tem medo de qualquer pessoa que chegue
\end{abstract} perto. (NO)

M: Aí, a enfermeira vem fazer o curativo, ela: ai, mãe, não deixa ela me mata, não deixa ela me mata.(EM)

Todo esse sofrimento faz com que a criança acabe Percebendo-se pequena, menor até mesmo do que determina sua pequenez física, cercada de situações que não deseja e é impotente para evitar. São também desencadeantes de Percebendose pequena, outras situações cuja ocorrência a criança é impotente para impedir, tais como: ser levada, sem opção, para o hospital; ter que permanecer presa dentro do hospital, pelo fato de ser criança, e, portanto intrinsecamente pequena como são as crianças e, ainda, não conseguir entender o que está ocorrendo e nem poder impedir a dor, a reclusão, as restrições, os procedimentos indesejados. Enquanto isso, os adultos, que são grandes, não pequenos como ela, até podem sair do hospital.

P: A.P., você já andou nesse carro? $\mathbf{C}$ balança positivamente a cabeça. P: Quando? C: Deize horas(segundo a mãe esse foi o horário que saíram de Itajubá para vir para o hospital). P: Por que você andou? C: Porque ficou internada.P: E por que ficou internada? C fica sem responder por um tempo. A seguir, olha e diz: Porque tem criança.P: Porque é criança ficou internada? $\mathbf{C}$ balança positivamente a cabeça. P: E todas as crianças ficam internadas? C balança positivamente a cabeça. P: Por quê? C: Porque não pode sair. A mãe pode sair, mas não pode comprar nada. (SB) 


\section{Enfrentando o mistério e o terror com a proteção da mãe}

O segundo momento representa a força da criança na vivência da hospitalização. Revela como a criança, embora percebendo-se pequena, encontra forças para enfrentar o mistério e o terror da hospitalização e como a mãe interage com ela no sentido de protegê-la e tentar facilitar-lhe a experiência. $\mathrm{O}$ fato de perceber-se tão pequena e impotente não a impede de mobilizar recursos próprios, Tentando compreender os fatos relativos ao seu misterioso corpo e aos procedimentos nele realizados, por meio de perguntas e observações acerca de tudo que está ocorrendo.

M: Ela quer saber de tudo. Ela sempre pergunta se a pressão dela tá boa ou tá alta. Outro dia ela perguntou: Mas afinal de contas, o que é esta tal de pressão, afinal (EM)

Ela também utiliza outro recurso com o qual está acostumada a contar, Buscando o apoio da mãe sempre que precisa de algo, solicitando verbalmente, procurando contato físico com ela, chorando e choramingando frente a algum desconforto ou quando está amedrontada, envolvendo a mãe em suas brincadeiras, inclusive nas sessões de brinquedo terapêutico.

C pede: Mãe, corta aqui. M: A tia ajuda $\mathbf{C}$ tenta cortar a fita. P: Quer que a tia ajude? C balança negativamente a cabeça e tenta cortar a fita, mas não consegue e pede: Mãe, corta. $\mathbf{M}$ corta uns pedaços da fita e fixa o escalpe. $\mathbf{C}$ instala o equipo de soro no escalpe e pede: Mãe, liga. (SB)

Em meio a toda essa situação de mistério e terror que a criança vive durante a hospitalização, como ela consegue resistir?, que ajuda ela recebe para suportar?; quem lhe oferece essa ajuda? Assim como num filme de mistério e de terror, alguém assume o papel de defesa e procura ajudar e proteger quem está sendo ameaçado. Na hospitalização da criança, esse papel é assumido por sua mãe ou, eventualmente, por outro membro da família que a substitui nos momentos em que ela se ausenta. Se observarmos as várias formas de interação da criança com a mãe durante a hospitalização, vemos que a presença desta permeia praticamente todas as outras interações, com exceção daquelas em que, por conta das regras ou das rotinas hospitalares, ela é impedida de estar presente. A mãe encontra ou cria brechas neste cerco para estar junto à criança.

Sendo protegida pela mãe espelha o nível das interações que a criança mantém com sua mãe e todo movimento desta, no sentido de protegê-la: estando o tempo todo a seu lado; procurando entender e

responder às suas necessidades não só de ordem física, como também emocionais; cuidando; apoiando; informando; confortando; acariciando; tentando facilitar as interações e mantendo seu vínculo com a família; falando por ela, quando não consegue fazê-lo; sofrendo junto sem se afastar.

M: Então eu vou explicando, não tento mentir nem enganar. Eu já falo porque mesmo que a linguagem seja, ela não entenda naquela hora, mas eu consigo transmitir uma certa confiança para ela, que ela sabe que o que eu tô falando pra ela está sendo feito, não tô enganando ela.(EM)

C chora e faz careta, olhando para o abdome. M: Doeu a barriguinha? AE aproxima-se e pergunta: ela está com o líquido? M: Está. Vai para o outro lado do berço e ajeita a posição da criança apoiando suas costas com um travesseiro. Olha para a pesquisadora e diz: É que faz pouco tempo que passou o cateter, ainda está dolorido.

Interagindo tão intensa e intimamente com sua mãe, a criança forma com ela um único cliente, um cliente diferente, muito maior, que ultrapassa as fronteiras determinadas pelas imposições da hospitalização, fazendo, portanto, com que a criança cresça perante as experiências e a equipe hospitalar. Assim, embora ela ainda seja e se perceba pequena, a presença da mãe, que em si própria já se constitui em uma forma de proteção, faz com que a criança não seja tão subjugada pelas experiências e pela dura rotina hospitalar, porque a mãe a protege e defende. É lógico que, contando com toda essa proteção, a criança tenha medo de ficar sem sua mãe, pois ficar sem ela é como estar ali somente em parte, aquela sua parte pequena e impotente, que fica cercada pelas experiências da hospitalização.

Além da proteção que recebe da mãe, ocorrem, eventualmente, algumas interações que se constituem em contingências facilitadoras da experiência para a criança: respondendo ao bem estar do corpo, brincando só ou com outra criança, recebendo apoio de outros e recebendo visitas.

E: Hoje, depois que nós voltamos do exame, a
mãe dele saiu para almoçar, então ele pediu para
mim: Vamos comigo lá fora para esperar a minha
mãe?Então ele me deu a mão e eu fiquei com ele
lá no corredor para esperar a mãe dele. Aí uma
hora ele pediu: Eu quero fazer xixi, você me leva
no banheiro, você fica comigo lá? Eu fui com ele,
ele fez xixi e nós voltamos para o corredor até a
mãe dele chegar. (NO)

Enfrentar todo o sofrimento diante do mistério e do terror da hospitalização e contar com a presença 
Circéa Amália Ribeiro Margareth Angelo protetora da mãe fazem com que a criança vá Tornando-se diferente, mais amadurecida, conhecendo palavras que normalmente não compõem o repertório das crianças de sua idade, como o nome de instrumentos, procedimentos e partes do corpo.

M: Teve um dia que ela quase parou lá, entrou em choque. Ela só pediu para a médica dar o oxigênio: Dá o cheirinho pra mim... É até agora eles estão levantando a perninha dela, ela mesmo pede. Olha, levanta minha perna, não tô passando bem. Aí ela já conhece o procedimento que tem que fazer.(EM).

Essa diferença também se manifesta quando ela passa a não reagir à realização dos procedimentos aos quais é submetida, dando a impressão de que eles não mais a incomodam; quando ela não consegue expressar o que está sentindo, ou quando passa a viver em constante estado de alerta, preocupada em identificar qualquer movimento das pessoas que indiquem a realização de um novo procedimento, demonstrando o quanto a despreocupação, tão própria da infância está prejudicada.

\section{C começa a desenhar. Técnica de labora- tório(TL) entra na enfermaria com um escalpe e uma luva na mão. C pára o desenho, fica parada e olha atenta e fixamente para ela. TL anda até o balcão da enfermaria e prepara material para uma coleta de sangue. C permanece olhando fixa- mente para ela e pergunta: Vai colher sangue de quem? (NO)}

Porém, a grande diferença é a que se opera na pessoa da criança, uma diferença marcante, representada pelo crescimento que a presença em si, e toda a atuação da mãe, a qual forma com ela uma unidade, determina, como demonstra este modelo teórico, Crescendo com a presença protetora da mãe.

\section{DISCUSSÃO DOS RESULTADOS}

O sofrimento da criança durante a hospitalização é um fato incontestável, que nem a própria mãe, nem nós, enfermeiros que amamos e nos interessamos pelo bem estar da criança podemos evitar totalmente. Entretanto, podemos tomar algumas medidas que a auxiliem a passar por ele de uma maneira mais suportável, e a primeira delas é permitir e facilitar que a mãe exerça junto à criança sua ação terapêutica.

Neste sentido, o modelo teórico Crescendo com a presença protetora da mãe não só confirma a ação terapêutica desempenhada pela mãe da criança hospitalizada, como amplia essa dimensão terapêutica, mostrando que ela determina um crescimento pessoal da criança, podendo assim ser comparada à exercida pelo terapeuta junto a seu cliente.
Conforme a terapia centrada no cliente, uma terapia está intimamente associada à estima mútua, forte e crescente entre o terapeuta e o cliente. $\mathrm{O}$ relacionamento entre o cliente e o terapeuta tornase terapêutico porque não é apenas uma abstração constituída ao se tomar conjuntamente dois indivíduos separados, mas por envolver um relacionamento emocional permeado de calor, compreensão, segurança contra os vários tipos de ataque, que vincula cliente e terapeuta, não sendo elemento de nada, mas sim, a terapia ${ }^{(30)}$.

Observando a maneira pela qual a criança hospitalizada e sua mãe interagem, identifica-se a estima mútua e forte existente entre elas; que esse relacionamento é permeado de calor, de compreensão e que é um ponto de referência onde a criança busca apoio durante os ataques determinados pelas difíceis e dolorosas experiências que ela se vê obrigada a enfrentar durante a hospitalização, fazendo com que a pessoa da criança cresça, com que seja um outro cliente, um cliente muito maior, como demonstra este modelo teórico. Mas, para tanto, a mãe também precisa ser cuidada, pois, durante a hospitalização ela tem que lidar tanto com o sofrimento da criança, como com seu próprio sofrimento, como demonstram vários estudos ${ }^{(13,31-33)}$.

Assim, o enfermeiro deve deixar de ser apenas um realizador de cuidados técnicos e passar a exercer também sua função como facilitador da experiência para a criança e para seus pais, o que se constitui num desafio, porque demanda numa mudança do enfoque da assistência de enfermagem tecnicista e centrado na patologia, para um enfoque centrado na da criança e na família.

Pensar as questões relativas à hospitalização da criança de três a seis anos, de uma forma interacionista permitiu que pudéssemos conhecer aspectos relativos ao significado de estar hospitalizada, para esta criança. E a TFD permitiu que conceitos relativos a estes aspectos fossem compreendidos e aprofundados. Permitiu também compreender que, apesar de sua pouca idade, de seu limitado desenvolvimento da comunicação verbal, e de seu característico modo de pensar, com pouca condição de abstração, a criança pré-escolar tem muito que nos dizer e é capaz de fazê-lo se estivermos dispostos a escutá-la e utilizarmos métodos adequados para observá-la e entrevistá-la.

Neste sentido, o BT mostrou-se como um excelente instrumento para a obtenção dos dados com crianças desta faixa etária, pois, foi brincando de uma criança que está no hospital que ela revelou quais situações eram particularmente difíceis de enfrentar durante a hospitalização e o quanto toda 
essa situação apresentava-se a ela como algo misterioso e aterrorizante. O brinquedo simbólico é um sistema muito complexo de "fala", por meio do qual a criança exterioriza e re-significa as relações e os papéis sociais internalizados por ela ${ }^{(25)}$. Nesta idade, para poder contar um caso ou uma estória, verbalmente, a criança necessita de objetos que estimulem a lembrança da situação, assim como da presença de um adulto que a auxilie na verbalização ${ }^{(27)}$.

Ressaltamos ainda que, embora não tenha sido nosso primeiro objetivo ao utilizá-lo no estudo, vemos o quanto o brinquedo foi realmente terapêutico para as crianças, pois, além de permitir que elas extravasassem os sentimentos advindos das situações que estavam vivenciando, favoreceu que a sensação de perceber-se pequena fosse amenizada, por satisfazer sua necessidade de crescer pe- rante elas, ao menos enquanto brincavam. A força que impulsiona e desencadeia a brincadeira é satisfazer a necessidade da criança pré-escolar de realizar atividades que ainda não pode, por ela ser criança ${ }^{(25)}$. Assim, a grande quantidade de dramatização de procedimentos evidenciou muito bem o quanto a vivência dos mesmos a levava a perceberse pequena, pois quando foi possível crescer, por intermédio da brincadeira, a criança assim o fez.

Com base nestas considerações, recomendamos a aplicação deste modelo teórico na prática assistencial à criança e à família, favorecendo que a mãe exerça sua ação terapêutica junto à criança, assim como que o Brinquedo Terapêutico integre sistematicamente a assistência à criança hospitalizada, no sentido de auxiliá-la a enfrentar o mistério e o terror da hospitalização.

\section{REFERÊNCIAS}

(1) Marlow D. Textbook of pediatric nursing. $5^{\text {th }}$ ed. Philadelphia: Saunders; 1977.

(2) Robertson J. Some responses to young children to loss of maternal care. Nurs Times 1953; 49(16): 382-6.

(3) Bowlby J. Cuidados maternos e saúde mental. $3^{\mathrm{a}}$ ed. São Paulo: Martins Fontes; 1995.

(4) Machado DVM, Machado EM. Cuidados psicológicos à criança hospitalizada. Rev Hosp Clin 1956; 11(44):205-8.

(5) Prugh DH. A study of the emotional reactions of children and families to hospitalization and illness. Am J Orthopsychiatr 1953; 23(1):70-106.

(6) Freiberg K. How parents react when their child is hospitalized. Am J Nurs 1975; 75(5):836-8.

(7) Jones DC. Effect of parental participation on hospitalized child behavior. Issues Compr Pediatr Nurs 1994; 17(2):81-92.

(8) Sheldon L. Hospitalizing children: a review of the effects. Nurs Stand 1997; 12(1):44-7.

(9) Callery P, Smith L. A study of role negotiation between nurses and the parents of hospitalized children. J Adv Nurs 1991; 16(7):772-81.

(10) Coyne IT. Parent participation in care: a critical review of the literature. J Adv Nurs 1995; 21(4): 716-22.

(11) Knight L. Child health: negotiating care roles. Nurs Times 1995; 91(27):31-3.
(12) Rocha ML. O significado do relacionamento difícil com as famílias de crianças com câncer. [dissertação] São Paulo (SP): Escola de Enfermagem da USP; 2000.

(13) Collet N. Criança hospitalizada: participação das mães no cuidado. [tese] Ribeirão Preto (SP): Escola de Enfermagem de Ribeirão Preto/USP; 2001.

(14) Angelo M. Hospitalização: uma experiência ameaçadora. In: Stern MHF. Quando a criança não tem vez: violência e desamor. São Paulo: Pioneira; 1986. p. 101-8.

(15) Bonn M. The effects of hospitalization on children: a review. Curationis 1994; 17(2):20-4.

(16) Veríssimo MLOR. A experiência de hospitalização, explicada pela própria criança. Rev Esc Enferm USP 1991; 25(2):153-68.

(17) Gomes ETL. Ouvindo crianças hospitalizadas. [dissertação] Ribeirão Preto (SP): Escola de Enfermagem de Ribeirão Preto/USP; 1993.

(18) Hart D, Bossert E. Self-reported fears of hospitalized school-age children. J Pediatr Nurs 1994; 9(2):83-90

(19) Oliveira H. Ouvindo a criança sobre a enfermidade e a hospitalização. In: Ceccim RB, Carvalho PRA. Criança hospitalizada: atenção integral como escuta à vida. Porto Alegre: Ed UFRGS; 1997. p. 42-55.

(20) Dupas G, Angelo M. Buscando superar o sofrimento impulsionada pela força do amor: a experiência da criança com câncer. Acta Oncol Bras 1997; 17(1):99-108. 
Circéa Amália Ribeiro Margareth Angelo
(21) Pereira SR. Reconstruindo o hospital: a ótica da criança portadora de doença renal crônica. [tese] São Paulo (SP): Departamento de Enfermagem/ UNIFESP; 1999.

(22) Alvarez REC. O significado do cuidado para a criança hospitalizada. [dissertação] São Paulo (SP): Escola de Enfermagem da USP; 2002.

(23) Angelo M. Vivendo uma prova de fogo: as experiências iniciais da aluna de enfermagem. [tese]. São Paulo (SP): Instituto de Psicologia da USP; 1989.

(24) Charon JM. Symbolic interacionism. $3^{\text {rd }}$ ed. Engleward Cliffs: Prentice-Hall; 1989.

(25) Vygotsky LS. A formação social da mente: o desenvolvimento dos processos psicológicos superiores. $5^{\mathrm{a}}$ ed. São Paulo: Martins Fontes; 1994.

(26) Ribeiro CA, Sabatés AL, Borba RIH, Rezende MA, Maia EBS. O brinquedo e a assistência de enfermagem à criança. Enferm Atual 2002; 2(24):6-17.

(27) Perroni MC. Desenvolvimento do discurso narrativo. São Paulo: Martins Fontes; 1992.
(28) Glaser BG. Theoretical sensitivity. Mill Valley: The Sociology Press; 1978.

(29) Ribeiro CA. Crescendo com a presença protetora da mãe: a criança enfrentando o mistério e o terror da hospitalização. [tese] São Paulo (SP): Escola de Enfermagem da USP; 1999.

(30) Wood JK. Abordagem centrada na pessoa. Vitória: Fundação Ceciliano Abel de Almeida/UFES; 1994.

(31) Bezerra LFR, Fraga MNO. Acompanhar um filho hospitalizado: compreendendo a vivência da mãe. Rev Bras Enferm 1996; 49(4):611-24.

(32) Oliveira I. Vivenciando com o filho uma passagem difícil e reveladora: a experiência da mãe acompanhante. Rev Esc Enferm USP 2000; 34(2):202-8.

(33) Pinto JP, Fernandes RAQ, Teixeira MB. A mãe e a punção venosa do filho hospitalizado: uma visão fenomenológica. Rev Paul Enferm 2001; 20(2):12-9. 